\title{
The crucial role of the spacer in tuning the length of self-assembled nanorods
}

Shuaiyuan Han, Gaëlle Mellot, Sandrine Pensec, Jutta Rieger, François Stoffelbach, Erwan Nicol, Olivier Colombani, Jacques Jestin and Laurent Bouteiller

\section{SUPPORTING INFORMATION}

Contents:

$\begin{array}{ll}\text { 1. Synthesis } & \text { S2 }\end{array}$

2. Light and neutron scattering experiments $\quad$ S11

3. FTIR experiments $\quad \mathrm{S} 16$

$\begin{array}{ll}\text { 4. References } & \text { S17 }\end{array}$ 


\section{Synthesis}

\subsection{Materials and methods}

The following reactants were used without purification: tolylene-2,4-diisocyanate (TDI, 98\%, Aldrich), triethylamine (TEA, 99\%, Aldrich), di-tert-butyl dicarbonate ( $\mathrm{Boc}_{2} \mathrm{O}$, 99\%, Acros), magnesium sulfate $\left(\mathrm{MgSO}_{4}, 97 \%\right)$, 2-chloropropionyl chloride (97\%, Aldrich), $\mathrm{HCl}$ in dioxane (4 M, Aldrich), 6-amino-1-hexanol (97\%, Aldrich), pentamethyl-diethylenetriamine (PMDETA, 99\%, Aldrich), 2,2'azobis(isobutyronitrile) (AIBN, $\quad \geq 98 \%, \quad$ Aldrich), 1-ethyl-3-(3dimethylaminopropyl)carbodiimide hydrochloride (EDC.HCl, $\geq 98 \%$, TCI), 4(dimethylamino)pyridine (DMAP, > 99\%, Fluka), N,N-dimethylformamide (DMF, VWR, Normapur), 1,3,5-trioxane ( $\geq 99 \%$, Aldrich) and 1,4-dioxane ( $\geq 99 \%$, Acros Organics). All the anhydrous solvents were used from a solvent purification system (MBraun SPS). CTA-0 was dried by three successive azeotropic distillations with dry toluene before use. Styrene $\left(>99 \%\right.$, Aldrich) was purified by basic $\mathrm{Al}_{2} \mathrm{O}_{3}$ chromatography or distillation before use.

$\mathrm{CuCl}$ (Aldrich) was purified by precipitating from concentrated hydrochloric acid $(14 \mathrm{~g}$ of crude $\mathrm{CuCl}$ were dissolved in $30 \mathrm{~mL}$ concentrated $\mathrm{HCl}$ aq. $300 \mathrm{~mL}$ of pure water were added into the solution leading to the formation of a white solid) and by washing with several solvents (water, ethanol and ether).

NMR analysis. ${ }^{1} \mathrm{H}$ and ${ }^{13} \mathrm{C}$ NMR spectra were recorded on a Bruker Avance 400 spectrometer.

Size exclusion chromatography (SEC). For polymers with $\mathrm{x} \sim 30$, measurements were performed with a Viscotek TDAmax system from Malvern Instruments that consists of an integrated solvent and sample delivery module (GPCmax) and a Tetra Detector Array (TDA) including a light scattering detector with a Right $\left(90^{\circ}\right)$ and a Low $\left(7^{\circ}\right)$ angle (RALS/LALS) and a laser at $670 \mathrm{~nm}$, a 4-capillary differential viscometer, a differential refractive index detector (RI) and a Diode Array UV Detector. THF was used as the mobile phase at a flow rate of $1 \mathrm{~mL} \cdot \mathrm{min}^{-1}$, toluene was used as a flow rate marker. All polymers were injected 4 times $(80,100,120$, and $140 \mu \mathrm{L})$ at a concentration of 10 g.L $\mathrm{L}^{-1}$ after filtration through a $0.22 \mu \mathrm{m}$ pore-size membrane. The separation was carried out on three Polymer Laboratories columns [3× PLgel $5 \mu \mathrm{m}$ Mixed C $(300 \times 7.5 \mathrm{~mm})]$ and a guard column $(\mathrm{PL}$ gel $5 \mu \mathrm{m})$. Columns and detectors were maintained at $40^{\circ} \mathrm{C}$.

For polymers with $\mathrm{x} \sim 10$, measurements were performed with a Viscotek TDA system from Malvern Instruments that consists of a Tetra Detector Array (TDA) including a light scattering detector with a Right $\left(90^{\circ}\right)$ and a Low $\left(7^{\circ}\right)$ angle (RALS/LALS) and a laser at $670 \mathrm{~nm}$, a 4 -capillary differential viscometer, a differential refractive index detector (RI) and a Diode Array UV Detector. Dimethylformamide (DMF) containing $1 \mathrm{~g} / \mathrm{L} \mathrm{LiBr}$ was used as the mobile phase at a flow rate of $0.8 \mathrm{~mL} \cdot \mathrm{min}^{-1}$, toluene was used as a flow rate marker. All polymers were injected 4 times $\left(1,2.5,5\right.$ and 10 g.L $\left.\mathrm{L}^{-1}\right)$ after filtration through a $0.22 \mu \mathrm{m}$ pore-size membrane. Two columns thermostated at $60^{\circ} \mathrm{C}$ (PSS GRAM, $1000 \AA, 8 \mathrm{~mm} \times 300 \mathrm{~mm}$ and PSS GRAM, $30 \AA, 8 \mathrm{~mm} \times 300 \mathrm{~mm}$ ) 
were used for separation.

In both cases, the OmniSEC 5.12 software was used for data acquisition and data analysis. The refractive index $(\mathrm{RI})$ increment $(\mathrm{dn} / \mathrm{dc})$ of each polymer was determined in line with the RI detector injecting various polymer concentrations $(\mathrm{dn} / \mathrm{dc}=0.13 \mathrm{~mL} / \mathrm{g}$ in THF and $0.17 \mathrm{~mL} / \mathrm{g}$ in DMF). The static light scattering detection was used to calculate $M_{\mathrm{n}}$. The molar mass distribution $\left(\bigoplus=M_{\mathrm{w}} / M_{\mathrm{n}}\right)$ was deduced from the RI signal using a PMMA (DMF system) or PS calibration (THF system).

\subsection{Synthesis of the ATRP initiators}

di-TDI. The procedure was adapted from a previous work. ${ }^{1}$ TDI (1.73 g, $\left.9.96 \mathrm{mmol}\right)$ and $9 \mathrm{~mL}$ of anhydrous diethylether were stirred in a dried $100 \mathrm{~mL}$ two-necked flask under argon. Water $(52 \mathrm{mg}, 2.88 \mathrm{mmol}$ ) dissolved in $30 \mathrm{~mL}$ of anhydrous diethyl ether were injected into the two-necked flask using a syringe with flow rate of $30 \mathrm{~mL} / \mathrm{h}$. After one-night stirring at room temperature, the solid was filtered with a Büchner funnel. A white powder $(0.54 \mathrm{~g}, 58.6 \%)$ was obtained.

${ }^{1} \mathrm{H}$ NMR (400 MHz, DMSO-d $)$ ): 8.72 (m, 2H, urea-H), 7.42 (m, 2H, Ar-H), 7.23-7.08 (m, $4 \mathrm{H}, \mathrm{Ar}-\mathbf{H}), 2.25$ (m, 6H, Ar- $\mathrm{CH}_{3}$ ) (mixture of isomers).

ULI. The long spacer initiator (ULI) has been synthesized in four steps (see Figure S1):

a)<smiles>CC(Cl)C(=O)C(C)C(C)(C)C(=O)OCCCCCCNC(=O)OC(C)(C)C</smiles><smiles>CC(Cl)C(=O)OCCCCCCN</smiles><smiles>CC(Cl)C(=O)OCCCCCCNC(=O)Nc1cccc(NC(=O)Nc2cccc(NC(=O)NCCCCCCOC(=O)C(C)Cl)c2)c1</smiles>

b)

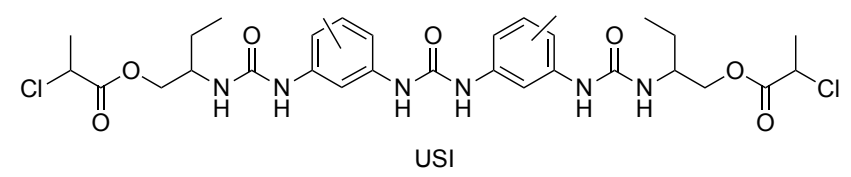

Figure S1. Synthesis scheme of long spacer initiator ULI (a) and structure of short spacer initiator USI (b). 
UL1. 6-Amino-1-hexanol (3.51 g, $30 \mathrm{mmol}$, 1eq) was dissolved in $100 \mathrm{~mL}$ of anhydrous dichloromethane (DCM) in a round bottom flask under argon. The solution was cooled to $0^{\circ} \mathrm{C}$ in ice bath, TEA $(4.15 \mathrm{~mL}, 30 \mathrm{mmol}, 1 \mathrm{eq})$ was added by syringe, then $\mathrm{Boc}_{2} \mathrm{O}$ (4.16 g, $\left.30 \mathrm{mmol}, 1 \mathrm{eq}\right)$ was added slowly. The solution was allowed to reach room temperature and stirred overnight. DCM was evaporated under reduced pressure and the product was dissolved in diethyl ether. Then the solution was washed with 75 $\mathrm{mL}$ of $1 \mathrm{M} \mathrm{HCl}$ and three times with $75 \mathrm{~mL}$ of distilled water. The organic layer was collected and dried with $\mathrm{MgSO}_{4} .6 .10 \mathrm{~g}(93.6 \%)$ of white waxy solid were obtained.

${ }^{1} \mathrm{H}$ NMR (400 MHz, $\mathrm{CDCl}_{3}$ ): 1.41-1.30 (m, 4H, $\mathrm{HOCH}_{2} \mathrm{CH}_{2} \mathrm{CH}_{2} \mathrm{CH}_{2} \mathrm{CH}_{2}-$ ), 1.45 (s, $\left.9 \mathrm{H}, \quad\left(\mathrm{CH}_{3}\right)_{3} \mathrm{C}-\right), \quad 1.61-1.53 \quad\left(\mathrm{~m}, \quad 2 \mathrm{H}, \quad-\mathrm{HNCH}_{2} \mathrm{CH}_{2} \mathrm{CH}_{2-}\right), \quad 1.52-1.46 \quad(\mathrm{~m}, \quad 2 \mathrm{H}$, $\mathrm{HOCH}_{2} \mathrm{CH}_{2} \mathrm{CH}_{2-}$ ), 1.88 (br s, $1 \mathrm{H}, \mathbf{H O C H}_{2}$ ), 3.11 (t, $J=7.2 \mathrm{~Hz}, 2 \mathrm{H},-\mathrm{HNCH}_{2} \mathrm{CH}_{2}-$ ), $3.63\left(\mathrm{t}, \mathrm{J}=7.2 \mathrm{~Hz}, 2 \mathrm{H}, \mathrm{HOCH}_{2} \mathrm{CH}_{2}-\right), 4.55\left(\mathrm{br} \mathrm{s}, 1 \mathrm{H},-\mathrm{CH}_{2} \mathrm{NHC}=\mathrm{O}\right)$.

UL2. UL1 (5.95 g, $27.4 \mathrm{mmol}$, 1eq) was dissolved in $30 \mathrm{~mL}$ anhydrous THF in a round bottom flask under argon. TEA $(3.80 \mathrm{~mL}, 27.4 \mathrm{mmol}, 1 \mathrm{eq})$ was added by syringe. The solution was cooled to $0^{\circ} \mathrm{C}$. 2-chloropropanoyl chloride $(2.70 \mathrm{~mL}, 27.4 \mathrm{mmol}$, 1eq) dissolved in $10 \mathrm{~mL}$ anhydrous THF was added in $1 \mathrm{~h}$ in the cooled flask. The solution was allowed to reach room temperature and stirred overnight. After filtration, the THF was removed, the crude product was dissolved in diethyl ether and washed three times with distilled water. The organic layer was collected and dried with $\mathrm{MgSO}_{4} .6 .15 \mathrm{~g}$ (74.1\%) of a yellow oil was obtained.

${ }^{1} \mathrm{H}$ NMR (400 MHz, $\left.\mathrm{CDCl}_{3}\right): 1.53-1.32\left(\mathrm{~m}, 15 \mathrm{H},-\mathrm{OCH}_{2} \mathrm{CH}_{2} \mathrm{CH}_{2} \mathrm{CH}_{2} \mathrm{CH}_{2} \mathrm{CH}_{2} \mathrm{NH}-+\right.$ $\left.\left(\mathrm{CH}_{3}\right)_{3} \mathrm{C}-\right)$, $1.78-1.63$ (m, 3H, $\left.\mathrm{CH}_{3} \mathrm{CHCl}\right), 3.19-3.05$ (m, $\left.2 \mathrm{H},-\mathrm{CH}_{2} \mathrm{CH}_{2} \mathrm{NH}-\right), 4.19$ (td, $\left.J 1=6.4 \mathrm{~Hz}, J 2=2.8 \mathrm{~Hz}, 2 \mathrm{H},-\mathrm{OCH}_{2} \mathrm{CH}_{2}-\right), 4.41\left(\mathrm{q}, J=6.8 \mathrm{~Hz}, 1 \mathrm{H}, \mathrm{CH}_{3} \mathrm{CHCl}\right), 4.55$ (br s, $1 \mathrm{H},-\mathrm{NH}-)$.

UL3. UL2 (6.00 g, $19.5 \mathrm{mmol}, 1 \mathrm{eq})$ was placed in a round bottom flask in an ice bath under argon. $15.50 \mathrm{~mL}$ of $4 \mathrm{M} \mathrm{HCl}$ in dioxane was added slowly. After addition, the mixture was stirred at room temperature overnight. Then dioxane was evaporated under reduced pressure, a bright yellow oil (4.42 g, 93\%) was obtained.

${ }^{1} \mathrm{H}$ NMR (400 MHz, DMSO-d 6 ): 1.39-1.26 (m, 4H, - $\left.\mathrm{CH}_{2} \mathrm{CH}_{2} \mathrm{CH}_{2} \mathrm{CH}_{2}-\right)$, 1.66-1.51 (m, $\left.7 \mathrm{H}, \mathrm{CH}_{3} \mathrm{CHCl}+-\mathrm{OCH}_{2} \mathrm{CH}_{2-}+{ }_{-} \mathrm{CH}_{2} \mathrm{CH}_{2} \mathrm{NH}_{3}{ }^{+}\right), 2.82-2.66\left(\mathrm{~m}, 2 \mathrm{H},-\mathrm{CH}_{2} \mathrm{NH}_{3}{ }^{+}\right), 4.13$ $\left(\mathrm{td}, J 1=6.4 \mathrm{~Hz}, J 2=2.8 \mathrm{~Hz}, 2 \mathrm{H},-\mathrm{OCH}_{2} \mathrm{CH}_{2}-\right), 4.72$ (q, $\left.J=6.8 \mathrm{~Hz}, 1 \mathrm{H}, \mathrm{CH}_{3} \mathrm{CHCl}\right), 8.12$ $\left(\mathrm{s}, 3 \mathrm{H},-\mathrm{NH}_{3}^{+}\right)$.

ULI. di-TDI (1.79 g, $8.66 \mathrm{mmol}$, 1eq) was dissolved in $320 \mathrm{~mL}$ of anhydrous THF under argon. A solution of UL3 (4.42 g, $18.18 \mathrm{mmol}, 2.1 \mathrm{eq})$ in $80 \mathrm{~mL}$ of anhydrous THF was added slowly by syringe to the di-TDI solution. TEA $(2.54 \mathrm{~mL}, 18.18 \mathrm{mmol})$ 
was added to the flask. After half an hour a white gel was generated. The flask was shaken at room temperature until FTIR spectroscopy revealed the absence of remaining isocyanate functions $\left(2270 \mathrm{~cm}^{-1}\right)$. The product was directly precipitated in $2.5 \mathrm{~L}$ of distilled water. A white powder $(4.99 \mathrm{~g}, 68 \%)$ was obtained by recrystallization from mixed solvents of DMF and water (10/1).

${ }^{1} \mathrm{H}$ NMR (400 MHz, DMSO-d 6 ): 1.52-1.26 (m, 12H, - $\mathrm{CH}_{2} \mathrm{CH}_{2} \mathrm{CH}_{2} \mathrm{CH}_{2} \mathrm{CH}_{2} \mathrm{NH}-$ ), 1.69 $1.52\left(\mathrm{~m}, 10 \mathrm{H},-\mathrm{CH}_{2} \mathrm{CH}_{2} \mathrm{CH}_{2} \mathrm{O}-+\mathrm{CH}_{3} \mathrm{CHCl}\right), 2.11$ (s, 6H, Ar- $\left.\mathrm{CH}_{3}\right), 3.15-3.01$ (m, 4H, $\left.-\mathrm{CH}_{2} \mathrm{CH}_{2} \mathrm{NH}-\right), 4.14$ (td, $\left.J 1=6.4 \mathrm{~Hz}, J 2=2.8 \mathrm{~Hz}, 4 \mathrm{H},-\mathrm{OCH}_{2} \mathrm{CH}_{2}-\right), 4.71$ (q, $J=6.8 \mathrm{~Hz}$, $\left.2 \mathrm{H}, \mathrm{CH}_{3} \mathrm{CHCl}\right), 6.54\left(\mathrm{t}, 2 \mathrm{H}, \mathrm{CH}_{2} \mathrm{NHC}=\mathrm{O}\right), 7.03-6.93(\mathrm{~m}, 2 \mathrm{H}, \mathrm{ArH}), 7.19-7.10(\mathrm{~m}, 2 \mathrm{H}$, $\operatorname{ArH}), 7.52$ (s, 2H, ArH), 7.84 (s, 2H, $\operatorname{ArNHC}=\mathrm{O}), 8.39$ (s, 2H, $\operatorname{ArNHC}=\mathrm{O})$.

${ }^{13} \mathrm{C}$ NMR (100 MHz, DMSO-d $\left.{ }_{6}\right)$ : $17.70\left(\mathrm{Ar}-\mathrm{CH}_{3}\right), 21.68\left(\mathrm{CH}_{3} \mathrm{CHCl}\right), 25.46$ ($\left.\mathrm{CH}_{2} \mathbf{C H}_{2} \mathrm{CH}_{2} \mathrm{CH}_{2} \mathrm{O}-\right)$, 26.47 ( $\left.-\mathrm{HNCH}_{2} \mathrm{CH}_{2} \mathbf{C H}_{2} \mathrm{CH}_{2}-\right), 28.36\left(-\mathrm{CH}_{2} \mathbf{C H}_{2} \mathrm{CH}_{2} \mathrm{O}-\right), 30.07$ $\left(-\mathrm{HNCH}_{2} \mathbf{C H}_{2} \mathrm{CH}_{2}-\right), 39.40\left(-\mathrm{HNCH}_{2} \mathrm{CH}_{2}-\right), 53.29\left(\mathrm{ClCHCH}_{3}\right), 65.91\left(-\mathrm{CH}_{2} \mathbf{C H}_{2} \mathrm{O}-\right)$, 110.64 (Ar-H), 112.08 (Ar-H), $120.09\left(\mathbf{A r}-\mathrm{CH}_{3}\right), 130.46(\mathbf{A r}-\mathrm{H}), 138.30(-\mathrm{N}-\mathbf{A r})$, 138.88 (-N-Ar), 152.85 (ArNH-CO-NH-Ar), 155.73 (NH-CO-NH), 170.05 (-OC=O).

USI. The short spacer initiator (USI, Figure S1) has been synthesized according to an already published procedure. ${ }^{1}$

\subsection{Synthesis of the TTC-U3-TTC RAFT agent}

The tris(urea) functional RAFT agent has been synthesized following the synthetic pathway displayed on Figure S2.
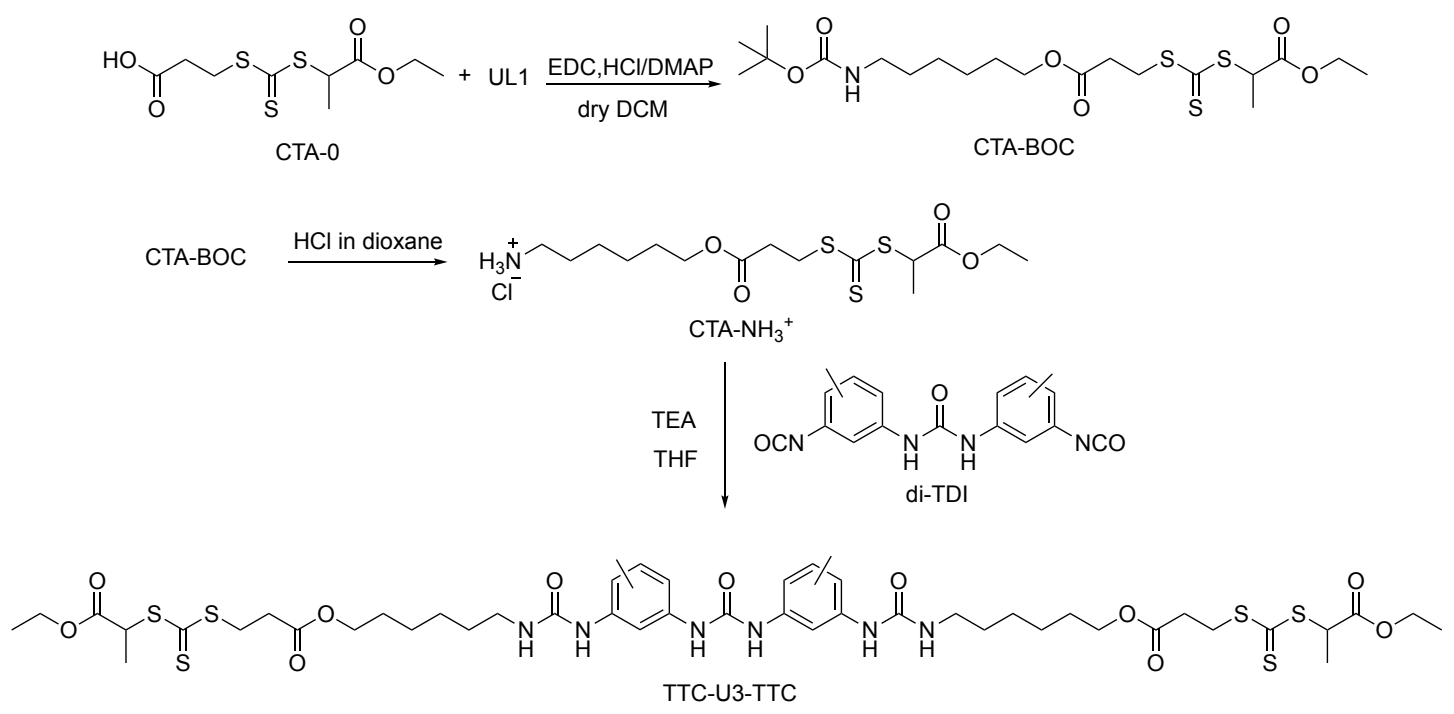

Figure S2. Synthesis scheme of RAFT agent TTC-U3-TTC.

CTA-BOC. The carboxylic acid functional RAFT agent CTA-0 (obtained by the procedure described by Mellot et al. ${ }^{2}$ ) and UL1 were dried via azeotropic distillation with toluene $(3 \times 30 \mathrm{~mL})$. In a $25 \mathrm{~mL}$ round bottomed flask a solution of UL1 (2.99 g, 
$13.8 \mathrm{mmol})$, EDC. HCl (2.92 g, $15.2 \mathrm{mmol})$ and DMAP (0.375 g, $3.07 \mathrm{mmol})$ in $20 \mathrm{~mL}$ of dry DCM was prepared. In a $100 \mathrm{~mL}$ round bottomed flask a solution of CTA-0 (4.50 $\mathrm{g}, 15.9 \mathrm{mmol})$ in $70 \mathrm{~mL}$ of dry DCM was prepared. The first solution was then added dropwise at $0^{\circ} \mathrm{C}$ to the second one. The reaction mixture was stirred vigorously during $12 \mathrm{~h}$ and the reaction was monitored by TLC (DCM/MeOH: 95/5). The organic phase was washed successively with several solutions: a dilute solution of $\mathrm{HCl}$ at $\mathrm{pH}=4$, deionized water, an aqueous solution of $\mathrm{Na}_{2} \mathrm{CO}_{3}$ at $\mathrm{pH}=8$ and brine. The organic phase was dried with $\mathrm{MgSO}_{4}$ and the solvent was evaporated to afford a crude product which was purified by flash chromatography (DCM/MeOH: 95/5). A dark yellow oil was obtained which was washed with pentane and then dried under vacuum $(4.72 \mathrm{~g}, 71 \%$ yield).

${ }^{1} \mathrm{H}$ NMR (400 MHz, $\mathrm{CDCl}_{3}$ ): 4.81 (q, 1H, -S-CH-), 4.5 (s, 1H, NH), 4.21 (q, 2H, $\left.\mathrm{OCH}_{2}-\mathrm{CH}_{3}\right), 4.09$ (t, 2H, - $\left.\mathrm{CH}_{2}-\mathrm{CH}_{2} \mathrm{O}-\right), 3.61$ (t, 2H, -S-CH2- $\left.\mathrm{CH}_{2}-\right), 3.12$ (m, 2H, -NH$\left.\mathrm{CH}_{2}-\mathrm{CH}_{2}-\right), 2.75$ (t, 2H, -C(O)CH$\left.{ }_{2}-\mathrm{CH}_{2}-\right), 1.65$ (d, 3H, CH-CH $), 1.63-1.22(\mathrm{~m}, 8 \mathrm{H},-$ $\left.\mathrm{CH}_{2}-\right), 1.44$ (s, 9H, -C-(CH$\left.)_{3}\right), 1.28$ (t, 3H, O-CH $\left.2-\mathrm{CH}_{3}\right)$.

${ }^{13} \mathrm{C}$ NMR (100 MHz, $\left.\mathrm{CDCl}_{3}\right): 221.50$ (-S-(C=S)-S-), 171.38-170.96 (- $\left.\mathrm{CO}_{2}-\mathrm{CH}_{2}-\right)$, 156.04 (-NH-CO $2-\mathrm{C}-), 79.06$ (-O-C- $\left.\left(\mathrm{CH}_{3}\right)_{3}\right), 64.99$ (-CH$\left.-\mathrm{CH}-\mathrm{C}(\mathrm{O})\right), 61.98\left(-\mathrm{O}-\mathrm{CH}_{2}-\right.$ $\left.\mathrm{CH}_{3}\right), 48.32$ (-S-CH-CO-), 40.54 (-NH-CH$\left.{ }_{2}^{-}\right), 33.10-31.64$ ( $\mathrm{S}-\mathrm{CH}_{2}-\mathrm{CH}_{2}-\mathrm{C}(\mathrm{O}), 30.04-$ $25.65\left(-\mathrm{NH}-\left(\mathrm{CH}_{2}\right)_{4}-\mathrm{OC}(\mathrm{O})\right), 17.04\left(-\mathrm{CH}-\mathrm{CH}_{3}\right), 14.11\left(-\mathrm{CH}_{2}-\mathrm{CH}_{3}\right)$.

CTA- $\mathrm{NH}_{3}{ }^{+}, \mathbf{C l}^{-}$. In a $250 \mathrm{~mL}$ round bottomed flask a solution of CTA-BOC (3.87 $\mathrm{g}$, $8.03 \mathrm{mmol}$ ) was prepared in 1,4-dioxane $(32 \mathrm{~mL})$. Then the flask was purged with argon for 20 minutes and put in an ice-water bath before the following addition. A solution of $\mathrm{HCl}$ in dioxane (4M, $160 \mathrm{~mL}, 0.64 \mathrm{~mol})$ was slowly added dropwise, with stirring. The reaction mixture was stirred vigorously during $3 \mathrm{~h}$ and the reaction was monitored by TLC (DCM/MeOH: 95/5). The remaining $\mathrm{HCl} /$ dioxane was evaporated under vacuum and a yellow oil was obtained (3.50 g, 100\% yield).

${ }^{1} \mathrm{H}$ NMR (400 MHz, DMSO-d 6 ): 7.80 (s, 3H, $\mathrm{CH}_{2}-\mathrm{NH}_{3}{ }^{+}$), 4.74 (q, 1H, -S-CH), 4.12 (q, $2 \mathrm{H},-\mathrm{O}-\mathrm{CH}_{2}-\mathrm{CH}_{3}$ ), 4.05 (t, 2H, $\left.-\mathrm{CH}_{2}-\mathrm{CH}_{2}-\mathrm{O}-\right), 3.58$ (t, 2H, $\left.-\mathrm{S}-\mathrm{CH}_{2}-\mathrm{CH}_{2}-\right)$, 2.8-2.6 (m, $\left.4 \mathrm{H},-\mathrm{NH}_{3}{ }^{+}-\mathrm{CH}_{2}-\mathrm{CH}_{2}-,-\mathrm{C}(\mathrm{O})-\mathrm{CH}_{2}-\mathrm{CH}_{2}-\right), 1.75-1.2\left(\mathrm{~m}, 8 \mathrm{H}, \mathrm{CH}_{2}\right), 1.54(\mathrm{~d}, 3 \mathrm{H}, \mathrm{CH}-$ $\left.\mathrm{CH}_{3}\right), 1.19$ (t, 3H, O-CH $\left.2-\mathrm{CH}_{3}\right)$.

${ }^{13} \mathrm{C}$ NMR (100 MHz, DMSO-d 6$): 221.72$ (-S-(C=S)-S-), $170.88\left(-\mathrm{CO}_{2}-\mathrm{CH}_{2}-\right), 170.02$ (-CO $-\mathrm{CH}-), 64.27$ (-CH $2-\mathrm{O}-\mathrm{C}(\mathrm{O})), 61.54$ (-O-CH$-\mathrm{CH}_{2}$ ), 47.82 (-S-CH-CO-), 39.52 $\left(-\mathrm{NH}_{3}{ }^{+}-\mathrm{CH}_{2}-\right)$, 33.17-31.69 ( $\left.\mathrm{S}-\mathrm{CH}_{2}-\mathrm{CH}_{2}-\mathrm{C}(\mathrm{O})\right), 27.82-24.81 \quad\left(-\mathrm{NH}-\left(\mathrm{CH}_{2}\right)_{4}-\mathrm{OC}(\mathrm{O})\right)$, $16.39\left(-\mathrm{CH}-\mathrm{CH}_{3}\right), 13.90\left(-\mathrm{CH}_{2}-\mathrm{CH}_{3}\right)$.

TTC-U3-TTC. CTA-NH ${ }_{3}{ }^{+}, \mathrm{Cl}^{-}$was dried via azeotropic distillations with toluene $(3 \mathrm{x}$ $10 \mathrm{~mL})$. Then a solution of CTA- $\mathrm{NH}_{3}{ }^{+}, \mathrm{Cl}^{-}(0.49 \mathrm{~g}, 1.2 \mathrm{mmol})$ in $30 \mathrm{~mL}$ of dry THF was prepared in a $100 \mathrm{~mL}$ round bottomed flask. Separately, a solution of di-TDI $(0.16 \mathrm{~g}$, $0.51 \mathrm{mmol})$ and TEA $(0.15 \mathrm{~mL}, 1 \mathrm{mmol})$, previously dried with molecular sieve (3 $\AA$ ), was prepared in dry THF $(17 \mathrm{~mL})$. This second solution was then added dropwise to 
the first one at $0^{\circ} \mathrm{C}$ and the reaction mixture was stirred overnight. The reaction was stopped when FTIR indicated the absence of remaining isocyanate functions $\left(2270 \mathrm{~cm}^{-}\right.$ $\left.{ }^{1}\right)$. The product was precipitated in water and dried under vacuum to afford a yellow solid $(0.55 \mathrm{~g}, 84 \%$ yield $)$.

${ }^{1} \mathrm{H}$ NMR (400 MHz, DMSO-d 6 ): 8.38 (s, 2H, -NH-), 7.84 (s, 2H, -CH-), 7.51 (s, 2H, NH-), 7.14-6.96 (d, 4H, -CH-CH-), 6.53 (t, 2H, -NH-), 4.73 (q, 2H, -S-CH), 4.13 (q, $\left.4 \mathrm{H},-\mathrm{O}-\mathrm{CH}_{2}-\mathrm{CH}_{3}\right), 4.05$ (t, 4H, - $\left.\mathrm{CH}_{2}-\mathrm{CH}_{2}-\mathrm{O}-\right), 3.57$ (t, 4H, -S-CH $\left.2-\mathrm{CH}_{2}-\right), 3.09$ (t, 4H, -NH-CH $2-), 2.77$ (t, 4H, -C(O)-CH $\left.\mathbf{C H}_{2}-\mathrm{CH}_{2}-\mathrm{S}-\right), 2.10$ (s, 6H, -CH $), 1.53-1.18$ (m, 16H, $\left.\mathrm{CH}_{2}\right), 1.53$ (d, 6H, CH-CH 3$), 1.18\left(\mathrm{t}, 6 \mathrm{H}, \mathrm{O}-\mathrm{CH}_{2}-\mathrm{CH}_{3}\right)$.

${ }^{13} \mathrm{C}$ NMR (100 MHz, DMSO-d $)$ : 221.69 (-S-(C=S)-S-), 170.86-170.01 (-CO $\left.\mathrm{CO}_{2}-\mathrm{CH}_{2-}\right)$, 155.22-152.34 $\left(\mathbf{C}=\mathrm{O}_{\text {urea }}\right), 138.40-110.07\left(\mathbf{C}_{\text {ar }}\right), 64.35\left(-\mathbf{C H}_{2}-\mathrm{O}-\mathrm{C}(\mathrm{O})\right), 61.52\left(-\mathrm{O}-\mathbf{C H}_{2}-\right.$ $\left.\mathrm{CH}_{3}\right), 47.80$ (-S-CH-CO-), 39.52 (-NH-CH$\left.{ }_{2}^{-}\right), 32.17-31.69$ (S-CH$-\mathrm{CH}_{2}-\mathrm{C}(\mathrm{O}), 29.61-$ $\left.25.11 \mathrm{NH}-\left(\mathrm{CH}_{2}\right)_{4}-\mathrm{OC}(\mathrm{O})\right), 17.23\left(-\mathrm{Ph}-\mathrm{CH}_{3}\right), 16.37\left(-\mathrm{CH}-\mathrm{CH}_{3}\right), 13.88\left(-\mathrm{CH}_{2}-\mathrm{CH}_{3}\right)$.

\subsection{General procedure for the ATRP polymerization of styrene}

For a targeted $\mathrm{DP}_{\mathrm{n}}$ of 10 from USI: USI $(0.30 \mathrm{~g}, 0.441 \mathrm{mmol}, 1 \mathrm{eq}), \mathrm{DMF}(2 \mathrm{~mL})$ and styrene (purified through basic $\mathrm{Al}_{2} \mathrm{O}_{3}, 1.84 \mathrm{~g}, 17.64 \mathrm{mmol}, 40 \mathrm{eq}$ ) were introduced in a schlenk flask sealed with a rubber septum and degassed by two freeze-pump-thaw cycles. PDMETA (92 $\mu \mathrm{L}, 0.441 \mathrm{mmol}$, leq) was introduced into the mixture under argon flow, then the mixture was degassed by one freeze-pump-thaw cycle. $\mathrm{CuCl}(43.6$ $\mathrm{mg}, 0.441 \mathrm{mmol}$, 1eq) was introduced into the mixture under argon flow, then the mixture was degassed by three freeze-pump-thaw cycles. The Schlenk flask was placed in an oil bath at $70^{\circ} \mathrm{C}$. Samples were withdrawn periodically from the reaction mixture to determine conversion by ${ }^{1} \mathrm{H}$ NMR and molar mass by SEC. After $50-60 \%$ conversion, the Schlenk was opened to air and about $50 \mathrm{~mL}$ of DCM were added. The solution was washed with brine (about $200 \mathrm{~mL}$ ) until the organic layer was copper free (yellow solution). The organic layer was collected and dried with $\mathrm{MgSO}_{4}$. After concentration to about $5 \mathrm{~mL}$, the product was precipitated in about $50 \mathrm{~mL}$ of methanol and dried under vacuum overnight. A white powder $\mathrm{S}_{10}(860 \mathrm{mg}, 62 \%)$ was obtained.

${ }^{1} \mathrm{H}$ NMR (400 MHz, CDCl $/$ DMSO-d $_{6}-1 / 9$ vol/vol): 8.40 (s, 2H, -NH), 7.88 (s, 2H, NH), 7.56 ( $\mathrm{s}, 2 \mathrm{H},-\mathrm{ArH}), 6.27-7.42$ (m, 133H, -NH, -ArH), 4.31-4.91 (m, 2H, ClCHAr), 3.61-4.08 (m, 6H, -OCH $2 \mathrm{CHNH}-), 1.16-2.31$ (m, 84H, $\operatorname{ArCHCH}_{2-},-\mathrm{ArCH}_{3}$, $\left.\mathrm{CH}_{3} \mathrm{CHC}=\mathrm{O}\right), 0.71-1.01\left(\mathrm{~m}, 12 \mathrm{H}, \mathrm{CH}_{3} \mathrm{CH}_{2-}, \mathrm{CH}_{3} \mathrm{CHCH}_{2} \mathrm{CH}-\right)$. See Figure S3. 


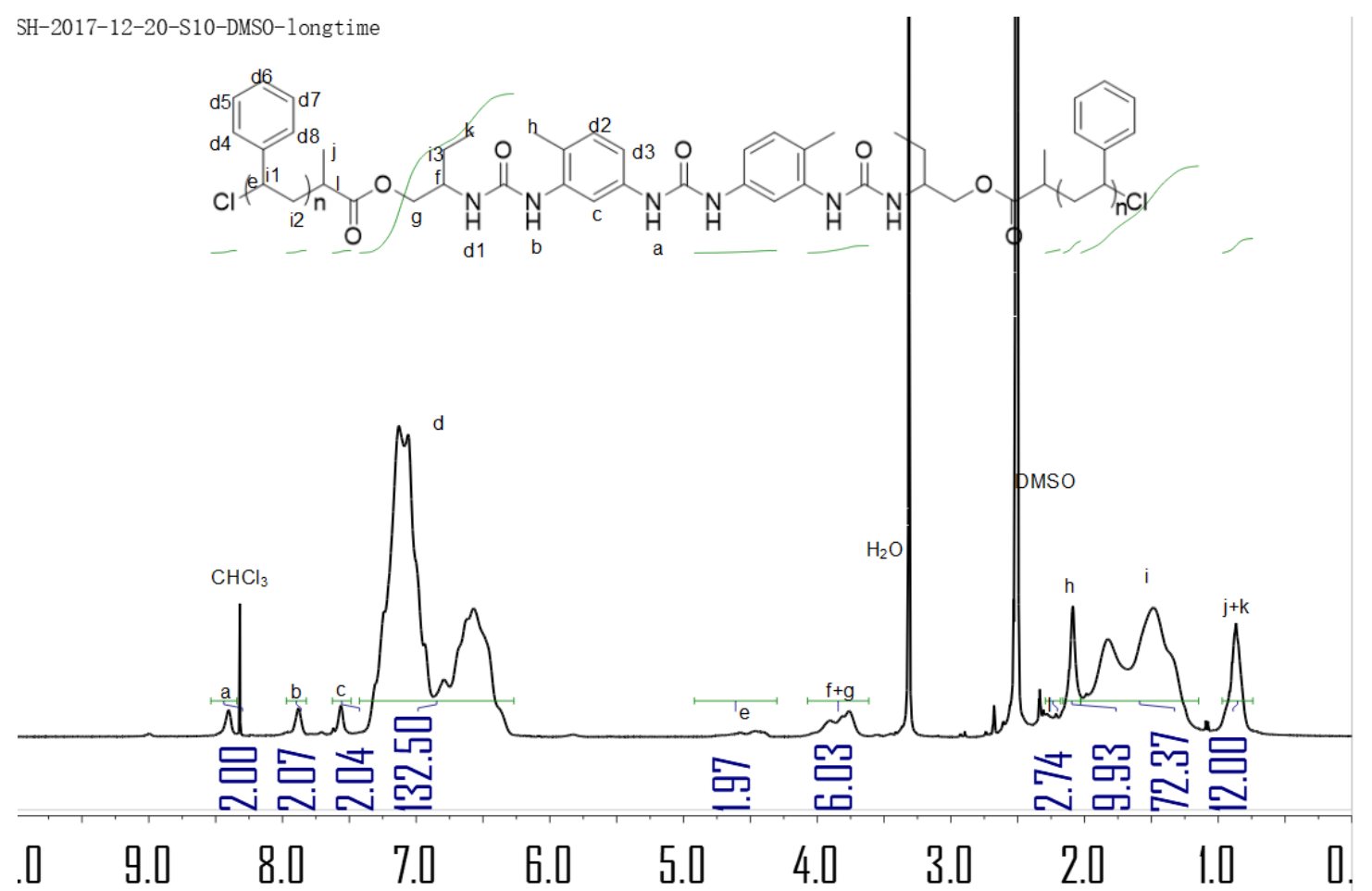

Figure S3. ${ }^{1} \mathrm{H}$ NMR of $\mathrm{S}_{10}\left(\mathrm{CDCl}_{3} / \mathrm{DMSO}-\mathrm{d}_{6} 1 / 9 \mathrm{vol} / \mathrm{vol}\right)$.

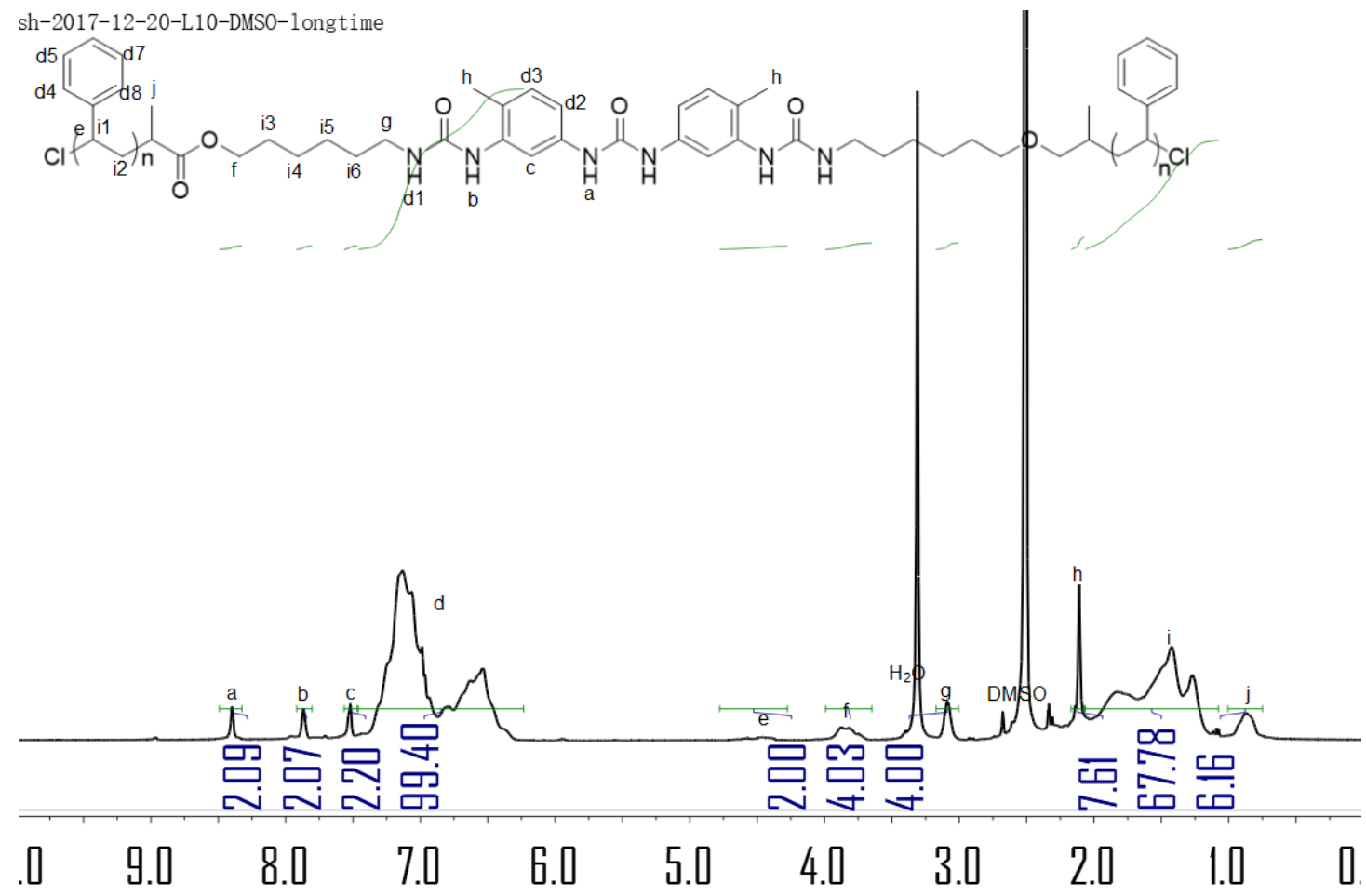

Figure S4. ${ }^{1} \mathrm{H}$ NMR of $\mathrm{L}_{10}\left(\mathrm{DMSO}-\mathrm{d}_{6}\right)$. 
Table S1. Characterization of polystyrenes prepared by ATRP

\begin{tabular}{cccccc}
\hline Name & Initiator & $\begin{array}{c}{[\mathrm{M}] /[\mathrm{I}] /[\mathrm{CuCl}] /} \\
{[\mathrm{PMDETA}]}\end{array}$ & $\begin{array}{c}\text { Conversion } \\
(\%)^{\mathrm{a}}\end{array}$ & $\begin{array}{c}M_{\mathrm{n}, \mathrm{th}} \\
(\mathrm{kg} / \mathrm{mol})^{\mathrm{b}}\end{array}$ & $\begin{array}{c}M_{\mathrm{n}, \mathrm{NMR}} \\
(\mathrm{kg} / \mathrm{mol})^{\mathrm{c}}\end{array}$ \\
\hline $\mathrm{L}_{10}$ & ULI & $40 / 1 / 1 / 1$ & 46 & 2.6 & $3.1^{\mathrm{d}}$ \\
$\mathrm{S}_{10}$ & USI & $40 / 1 / 1 / 1$ & 59 & 3.1 & $3.3^{\mathrm{e}}$ \\
$\mathrm{L}_{30}$ & ULI & $120 / 1 / 1 / 1$ & 50 & 7.0 & $8.0^{\mathrm{d}}$ \\
$\mathrm{S}_{30}$ & USI & $120 / 1 / 1 / 1$ & 50 & 6.9 & $7.5^{\mathrm{e}}$
\end{tabular}

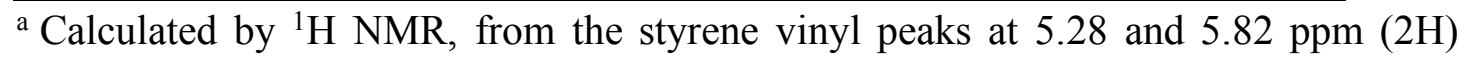
compared to the 6.28 to $7.61 \mathrm{ppm}$ peak (ArH of polystyrene $+\mathrm{ArH}$ of styrene + vinyl of styrene $(1 \mathrm{H}))$.

b Theoretical $M_{\mathrm{n}}$ at final conversion.

${ }^{\mathrm{c}}$ Calculated from the ${ }^{1} \mathrm{H}$ NMR of final polymer.

${ }^{d}$ Using the two methylene groups of the initiator at 3.00-3.16 ppm $\left(-\mathrm{CH}_{2} \mathrm{NH}-\right)$ as a reference $(4 \mathrm{H})$ and the peaks at $6.27-7.42 \mathrm{ppm}\left(\mathrm{m}, \mathrm{ArH}\right.$ of polystyrene, $-\mathrm{CH}_{2} \mathrm{NH},-\mathrm{ArH}$ from UL1): $M_{\mathrm{n}}=(\mathrm{n}-6) / 5 \times 104.06+722$.

${ }^{\mathrm{e}}$ Using the four methyl groups of the initiator at $0.71-1.01 \mathrm{ppm}$ as a reference $(12 \mathrm{H})$ and the peaks at 6.27-7.42 ppm (m, ArH of polystyrene, - CHNH, -ArH from US1): $M_{\mathrm{n}}$ $=(\mathrm{n}-6) / 5 \times 104.06+680$. 


\subsection{General procedure for the RAFT polymerization of styrene}

In a typical experiment (for a targeted $\mathrm{DP}_{\mathrm{n}}$ per arms of 30), TTC-U3-TTC (0.154 g, $0.142 \mathrm{mmol})$ was placed in a $10 \mathrm{~mL}$ round bottomed flask. $1,3,5$-Trioxane $(0.170 \mathrm{~g}$, $1.85 \mathrm{mmol}$ ) was then added. A solution of AIBN (23.1 mg, $0.14 \mathrm{mmol})$ in $23.6 \mathrm{~g}$ of DMF was prepared. $2.39 \mathrm{~g}$ of this solution $\left(1.39 \times 10^{-5} \mathrm{~mol}\right.$ of AIBN) was added in the flask containing the RAFT agent. Then, distilled styrene $(3.15 \mathrm{~mL}, 27.4 \mathrm{mmol})$ was added. After deoxygenation by bubbling with nitrogen for $25 \mathrm{~min}$, in an ice bath, the sealed flask containing the reaction mixture was immersed in a thermostaticallycontrolled oil bath at $80^{\circ} \mathrm{C}$. Samples were periodically withdrawn to monitor the conversion by ${ }^{1} \mathrm{H}$ NMR in DMSO- $\mathrm{d}_{6}$. The conversion was determined by the relative integration of the protons of 1,3,5-trioxane at $5.1 \mathrm{ppm}$ and the vinylic protons of styrene at 5.3, 5.9, and $6.7 \mathrm{ppm}$, respectively. The polymerization was stopped at $c a .30 \%$ conversion through quenching by immersion of the flask in iced water. The polymers were recovered by precipitation in methanol, then dried under vacuum and characterized by ${ }^{1} \mathrm{H}$ NMR in $\mathrm{CDCl}_{3} / \mathrm{DMSO}-\mathrm{d}_{6} \quad 1 / 9 \mathrm{vol} / \mathrm{vol}$ and size exclusion chromatography (SEC) in THF.

Table S2. Characterization of polystyrenes prepared by RAFT

\begin{tabular}{cccccc}
\hline name & agent & {$[\mathrm{M}] /[\mathrm{CTA}] /[\mathrm{I}]$} & $\begin{array}{c}\text { Conversion } \\
(\%)^{\mathrm{a}}\end{array}$ & $\begin{array}{c}M_{\mathrm{n}, \mathrm{th}} \\
(\mathrm{kg} / \mathrm{mol})^{\mathrm{b}}\end{array}$ & $\begin{array}{c}M_{\mathrm{n}, \mathrm{NMR}} \\
(\mathrm{kg} / \mathrm{mol})^{\mathrm{c}}\end{array}$ \\
\hline $\mathrm{R}_{10}$ & TTC-U3-TTC & $860 / 10 / 1$ & 29 & 3.7 & 4.4 \\
$\mathrm{R}_{30}$ & TTC-U3-TTC & $1940 / 10 / 1$ & 29 & 6.9 & 8.3 \\
\hline
\end{tabular}

${ }^{\text {a }}$ Calculated by ${ }^{1} \mathrm{H}$ NMR.

b Theoretical $M_{\mathrm{n}}$ at final conversion.

${ }^{\mathrm{c}}$ Calculated from the ${ }^{1} \mathrm{H}$ NMR of final polymer. 


\section{Light and neutron scattering experiments}

\subsection{Treatment of the light scattering data}

\section{Static light scattering (SLS)}

The absolute intensity, $R_{\theta}$ in $\mathrm{cm}^{-1}$, scattered by the polymer was determined according to (Equation $\mathbf{S 1}$ ).

$$
R_{\theta}=\frac{I_{\text {solution }}(\theta)-I_{\text {solvent }}(\theta)}{I_{\text {toluene }}(\theta)} \times\left(\frac{n_{\text {solvent }}}{n_{\text {toluene }}}\right)^{2} R_{\text {toluene }}
$$

(Equation S1)

With $I_{\text {solution }}, I_{\text {solvent }}$ and $I_{\text {toluene }}$ the average intensities scattered, respectively, by the solution, the solvent, and the reference (toluene) at angle $\theta ; \mathrm{n}_{\text {solvent }}=\mathrm{n}_{\text {toluene }}=1.496$ corresponds to the refractive index of the solvent which is also the reference; and $R_{\text {toluene }}$ $=1.35 \times 10^{-5} \mathrm{~cm}^{-1}$ the Rayleigh ratio of toluene for a wavelength $\lambda=633 \mathrm{~nm}$.

\section{Dynamic light scattering (DLS)}

The normalized electric field autocorrelation functions $\left(g_{1}(t)\right)$ obtained by DLS measurements were analyzed in terms of a relaxation time $(\tau)$ distribution: $g_{1}(t)=$ $\int A(\tau) e^{\left(\frac{-t}{\tau}\right)} d \tau$.

For all solutions except $\mathrm{S}_{30}$, only one $\mathrm{q}^{2}$-dependent relaxation mode was observed. The REPES routine was mainly used to obtain $A(\tau)$ without assuming a specific shape for the distribution. ${ }^{3}$ The apparent diffusion coefficient $\mathrm{D}$ was calculated from the average relaxation rate of this relaxation mode as $\mathrm{D}=\left\langle\tau^{-1}\right\rangle / \mathrm{q}^{2}$. $\mathrm{D}$ is related to the apparent hydrodynamic radius, $\mathrm{R}_{\mathrm{app}}$, of the solute according to (Equation $\mathbf{S 2}$.

$$
R_{a p p}=\frac{k_{B} T}{6 \pi \eta D}
$$

\section{(Equation S2)}

With k Boltzmann constant, $\mathrm{T}$ the absolute temperature and $\eta$ the viscosity of the solvent. When the particles are small compared to $\mathrm{q}^{-1}$ and the solutions are sufficiently diluted so that interactions can be neglected, $R_{a p p}$ is equal to the z-average hydrodynamic radius, $\mathrm{R}_{\mathrm{h}}$.

(Equation $\mathbf{S 3}$ was used in order to estimate the length of the cylinders formed by $\mathrm{L}_{10}$, $\mathrm{R}_{10}$ and $\mathrm{S}_{10}$ in toluene from $\mathrm{R}_{\mathrm{h}}$ assuming that the cylinders are long and rigid. ${ }^{4}$

$$
R_{h}=\frac{L}{2 \sigma-0.19-\frac{8.24}{\sigma}+\frac{12}{\sigma^{2}}}
$$

\section{(Equation S3)}

With $\sigma=\ln \left(\frac{L}{r}\right)$, L the length of the cylinder and $\mathrm{r}$ its cross sectional radius.

For $\mathrm{S}_{30}$, two populations of scattering particles were observed by DLS, a slow and a fast one. It was observed that the slow mode of relaxation corresponded to $\mathrm{R}_{\text {app }}$ values about 10 times as large as those of the fast mode of relaxation. As a conclusion, even though the slow mode of relaxation contributes significantly to the DLS and SLS 
signals because of its large molecular weight, its weight percentage within the sample can be neglected. The SLS and DLS data presented in the manuscript therefore correspond to the contribution of the fast mode of relaxation assuming that the contribution of the slow mode in terms of weight concentration is negligible. A similar behavior has already been observed in the literature for many other self-assembling systems and the same treatment was applied to get rid of the contribution of the large aggregates. $^{5}$

\subsection{Concentration dependency investigated by light scattering}

$\mathrm{L}_{10}$ and $\mathrm{L}_{30}$ were investigated by light scattering at different concentrations to determine the concentration range where repulsive interactions can be neglected. The apparent molecular weight was the same for $\mathrm{L}_{10}\left(\right.$ resp. $\mathrm{L}_{30}$ ) at 0.25 and $1 \mathrm{~g} / \mathrm{L}$ (resp. 1 and $10 \mathrm{~g} / \mathrm{L}$ ) (see Figure S5); indicating that repulsive interactions can be neglected in this concentration range. Moreover, $\mathrm{L}_{\mathrm{x}}$ forms the longest and most aggregated structures for a given $x$ value (see manuscript), so that repulsive interactions must also be negligible in the same concentration range for $\mathrm{R}_{\mathrm{x}}, \mathrm{S}_{\mathrm{x}}$ and $\mathrm{N}_{\mathrm{x}}$.

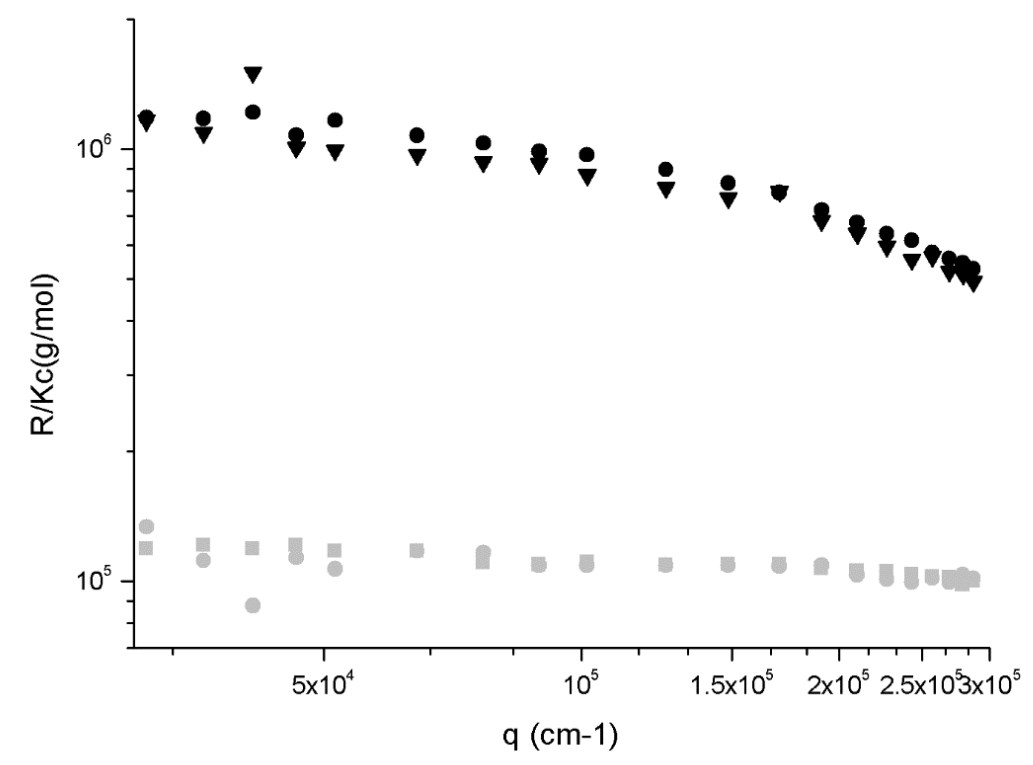

Figure S5. Evolution of $\mathrm{R}_{\theta} / \mathrm{KC}$ of $\mathrm{L}_{10}$ and $\mathrm{L}_{30}$ in toluene versus the scattering wave vector q, and for various concentrations $(\mathrm{C})$ : ( $) \mathrm{L}_{10} 0.25 \mathrm{~g} / \mathrm{L},(\bullet) \mathrm{L}_{10} 1 \mathrm{~g} / \mathrm{L},(\bullet) \mathrm{L}_{30}$ $1 \mathrm{~g} / \mathrm{L},(\square) \mathrm{L}_{30} 10 \mathrm{~g} / \mathrm{L} . \mathrm{K}$ is a constant defined in Equation S5.

\subsection{Thermal stability investigated by light scattering}

Polymer solutions in toluene were prepared by direct dissolution overnight in toluene at room temperature. They were measured either directly after their dissolution or after heating for $1 \mathrm{~h}$ at $50^{\circ} \mathrm{C}$. All measurements were conducted at $20^{\circ} \mathrm{C}$. Figure S6 reveals no impact of the treatment at $50^{\circ} \mathrm{C}$ on the characteristics of the self-assemblies. 


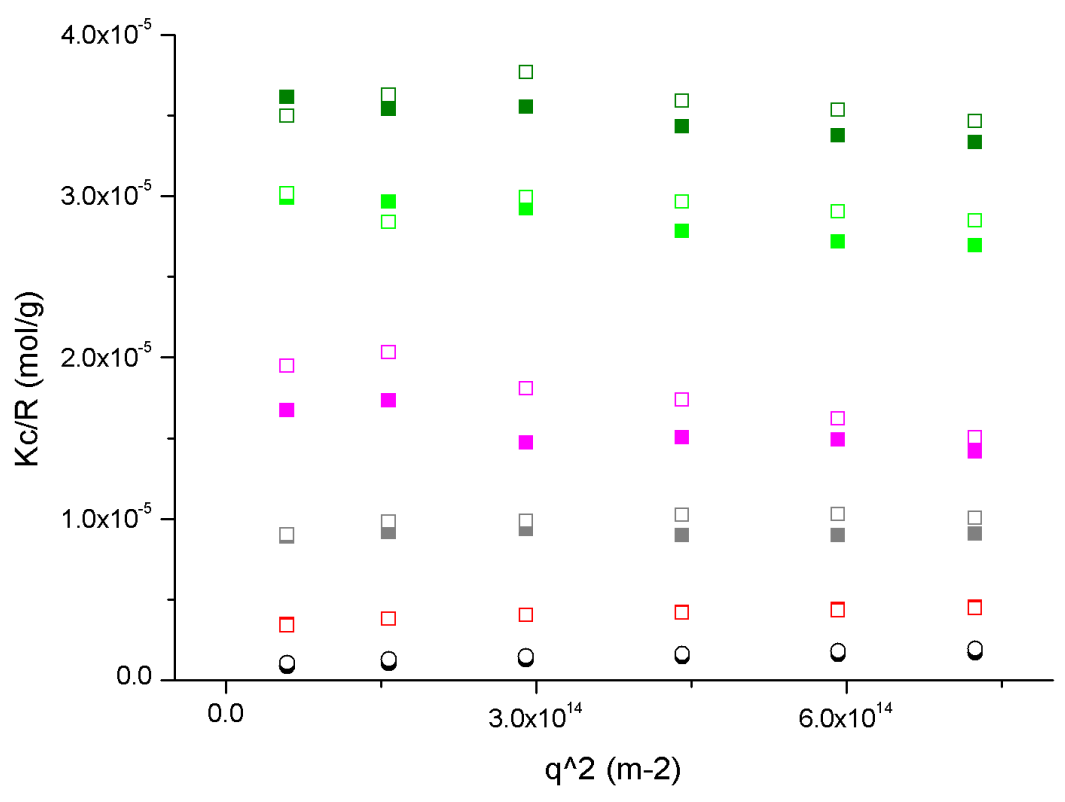

Figure S6. Evolution of $\mathrm{KC} / \mathrm{R}_{\theta}$ versus $\mathrm{q}^{2}$ determined by static light scattering in toluene at $20^{\circ} \mathrm{C}$ for samples prepared and stored at $20^{\circ} \mathrm{C}$ (filled symbols) or heated for $1 \mathrm{~h}$ at $50^{\circ} \mathrm{C}$ before measurement at $20^{\circ} \mathrm{C}$ (empty symbols) for $(\bullet, \circ) \mathrm{L}_{10} 1 \mathrm{~g} / \mathrm{L},(\square, \square) \mathrm{S}_{10} 10 \mathrm{~g} / \mathrm{L}$, $(\square, \square) \mathrm{N}_{10} 10 \mathrm{~g} / \mathrm{L},(\square, \square) \mathrm{L}_{30} 10 \mathrm{~g} / \mathrm{L},(\square, \square) \mathrm{S}_{30} 10 \mathrm{~g} / \mathrm{L}$ and $(\square, \square) \mathrm{N}_{30} 10 \mathrm{~g} / \mathrm{L}$.

\subsection{Combination and fitting of the SLS and SANS experiments}

\section{4.a) Superimposition of the SLS and SANS data}

The absolute intensity I obtained both from SLS and SANS experiments is related to the polymer concentration $\mathrm{C}$ in $\mathrm{g} . \mathrm{cm}^{-3}$, to a contrast factor $\mathrm{K}$, to the apparent weight average molecular weight of the scatterers extrapolated to $\mathrm{q} \rightarrow 0, \mathrm{M}_{\mathrm{app}}$, and to their form factor $\mathrm{P}(\mathrm{q})$, which depends on their shape and size (see below). ${ }^{6}$ Note that the apparent molecular weight $\mathrm{M}_{\mathrm{app}}$ corresponds to the true molecular weight $\mathrm{M}_{\mathrm{w}}$ only in very dilute solutions where the interactions between the scatterers can be neglected. ${ }^{6}$

$$
I=K \cdot C \cdot M_{a p p} \times P(q)
$$

(Equation S4)

For SLS:

$$
K_{S L S}=\frac{4 \pi^{2} n_{\text {solvent }}^{2}}{\lambda^{4} \mathrm{~N}_{\mathrm{a}}} \times\left(\frac{\partial n}{\partial C}\right)^{2}
$$

Where $\mathrm{N}_{\mathrm{a}}$ is Avogadro number and $\frac{\partial n}{\partial C}$ is the refractive index increment of the polymer in the solvent. We used the value for PS homopolymer in toluene $\frac{\partial n}{\partial C}=0.11 \mathrm{~mL} / \mathrm{g}$ for all samples. ${ }^{7}$ 
For SANS:

$$
K_{\text {SANS }}=\frac{\overline{\Delta b}^{2}}{\mathrm{~N}_{\mathrm{a}}}
$$

\section{(Equation S6)}

where $\overline{\Delta b}=\mathrm{b}_{2}-\rho_{2} / \mathrm{d}_{2}$ is the specific contrast of the polymer in the solvent with $\mathrm{b}_{2}$ the specific scattering length of the polymer $\left(\mathrm{cm} \cdot \mathrm{g}^{-1}\right), \mathrm{d}_{2}$ is its specific gravity $\left(\mathrm{g} \cdot \mathrm{cm}^{-3}\right)$, and $\rho_{\mathrm{s}}$ is the scattering length per unit volume of the solvent $\left(\mathrm{cm} . \mathrm{cm}^{-3}\right)$. The specific gravity $\mathrm{d}_{2}=1.04 \mathrm{~g} \cdot \mathrm{cm}^{-3}$ and $\overline{\Delta b}^{2}=1.68 \times 10^{21} \mathrm{~cm}^{2} \cdot \mathrm{g}^{-2}$ of PS homopolymer were used for all samples, yielding $\mathrm{K}_{\text {SANS }}=2.79 \times 10^{-3} \mathrm{~mol} \cdot \mathrm{cm}^{2} \cdot \mathrm{g}^{-2}$.

The curves of $\frac{I}{K . C}=\mathrm{f}(\mathrm{q})$ for SLS and SANS did not superimpose perfectly for the different samples, which could mainly be attributed to the intrinsic experimental error of both techniques $(\sim 10-20 \%)$ and to the fact that the values of $\mathrm{K}_{\text {SLS }}$ and $\mathrm{K}_{\text {SANS }}$ were assumed to be those of PS homopolymer neglecting the impact of the associating groups on these values. For $\mathrm{L}_{10}, \mathrm{R}_{10}$ and $\mathrm{S}_{10}$, it must also be pointed out that SANS experiments were conducted at $\sim 10 \mathrm{~g} / \mathrm{L}$; which could result in repulsive interactions causing the apparent values determined by SANS to be underestimated compared to the SLS data conducted in a concentration range where repulsive interactions were shown to be negligible. However, the discrepancy between SLS and SANS was similar for the other samples where repulsive interactions were shown to be negligible at $10 \mathrm{~g} / \mathrm{L}$. All SANS data were therefore slightly corrected to allow proper superposition with the SLS ones. For $\mathrm{S}_{30}$, as mentioned in section 2.1. of these Supporting Information, a population of so-called "spurious scatterers" which contribute significantly in terms of light scattering but are negligible in terms of mass concentration, were observed. Their contribution could be removed from the SLS data using DLS. However, the same treatment could not be applied to the SANS data for which the spurious scatterers still contributed up to $\mathrm{q} \sim 2.4 \times 10^{-2} \AA^{-1}$. The SANS data ranging from $\mathrm{q} \sim 5.5 \times 10^{-3} \AA^{-1}$ to $\mathrm{q} \sim 2.4 \times 10^{-2} \AA^{-1}$ were therefore not used for $\mathrm{S}_{30}$.

The superimposed SLS and SANS data were fitted using the open source SASView Software (http://www.sasview.org/).

\section{4.b) Model of monodisperse cylinders and estimation of $M_{\text {lin }}$}

A model of homogeneous cylinders with uniform contrast ${ }^{6,8}$ was used to fit the data for $\mathrm{L}_{10}, \mathrm{R}_{10}$ and $\mathrm{S}_{10}$, with the weight average molar mass $\mathrm{M}_{\mathrm{w}}$ of the cylinders, their length $\mathrm{L}$ and their radius $\mathrm{r}$ as fitting parameters. The quality of the fit was not strongly improved by imposing a dispersity on $\mathrm{L}$ or $\mathrm{r}$. We therefore used the simpler model of monodisperse cylinders.

For $\mathrm{S}_{10}$, it was not possible to fit the data correctly even by introducing a very strong dispersity in $\mathrm{L}$ or $\mathrm{r}$. Moreover, as mentioned previously, $\mathrm{S}_{30}$ contains a small proportion of spurious aggregates affecting the SLS data on the whole q-range and part of the 
SANS data on the lowest values of the q-range. We therefore hypothesized that $\mathrm{S}_{10}$ also contains a small proportion of spurious aggregates but that their size was not sufficiently different from that of the main population of cylinders in $\mathrm{S}_{10}$, preventing separation of both modes by DLS. The experimental data for $S_{10}$ could indeed be fitted by combining the contributions of monodisperse cylinders with that of spurious aggregates with a $\mathrm{R}_{\mathrm{g}}=90 \mathrm{~nm}$ (Guinier form factor).

When the cylinders are very long, the model of homogenous cylinders used in SASView can be simplified into (Equation S7) valid for infinitely long cylinders. ${ }^{9}$

$$
\begin{aligned}
& I=\frac{\pi C}{q} \cdot \mathrm{K} \cdot M_{L}\left[2 \frac{J_{1}(q r)}{q r}\right]^{2} \\
& (q I)_{q \rightarrow 0}=(q I)_{0} \exp \left(-\frac{\mathrm{r}^{2}}{4} q^{2}\right) \\
& (q I)_{0}=\pi C \cdot \mathrm{K} \cdot M_{L}
\end{aligned}
$$

Where $\mathrm{C}$ is the polymer concentration $\left(\mathrm{g} \cdot \mathrm{cm}^{-3}\right), \mathrm{M}_{\mathrm{L}}$ is the molecular weight per unit length of the cylinder $\left(\mathrm{g} \cdot \mathrm{mol}^{-1} \cdot \mathrm{nm}^{-1}\right), \mathrm{r}$ is the radius of the cross section, $\mathrm{K}$ is the contrast defined as in Erreur ! Source du renvoi introuvable. and S6) and $\mathrm{J}_{1}$ is the Bessel function of the first kind. These equations were successfully applied to fit the q-range where I.q is constant (that is $I$ is $q^{-1}$-dependent) for $L_{10}, R_{10}$ and $S_{10}$ yielding the radius of the cross-section of the cylinders and the molecular weight per unit of length.

Moreover, two consecutive ureas interacting through hydrogen bonds in a 1D structure are separated by an intermolecular distance of $0.46 \mathrm{~nm} .{ }^{10}$ The number of molecules in the cross-section $\mathrm{n}_{\mathrm{cs}}$ of the cylinders could be determined assuming that the tris(urea)s are also separated by a distance of $0.46 \mathrm{~nm}$ because they form hydrogen bonds parallel to the axis of the cylinders: $\mathrm{n}_{\mathrm{cs}}=\mathrm{M}_{\mathrm{L}} \times 0.46 / \mathrm{M}_{\mathrm{w} \text {,unimer. }}$.

\section{4.c) Model of monodisperse spheres}

A model of monodisperse spheres was used in SASView for $\mathrm{N}_{10}, \mathrm{~L}_{30}, \mathrm{R}_{30}, \mathrm{~S}_{30}$ and $\mathrm{N}_{30}$ with the weight average molar mass $M_{\mathrm{w}}$ of the spheres and their radius $\mathrm{r}$ as fitting parameters. 


\section{FTIR experiments}

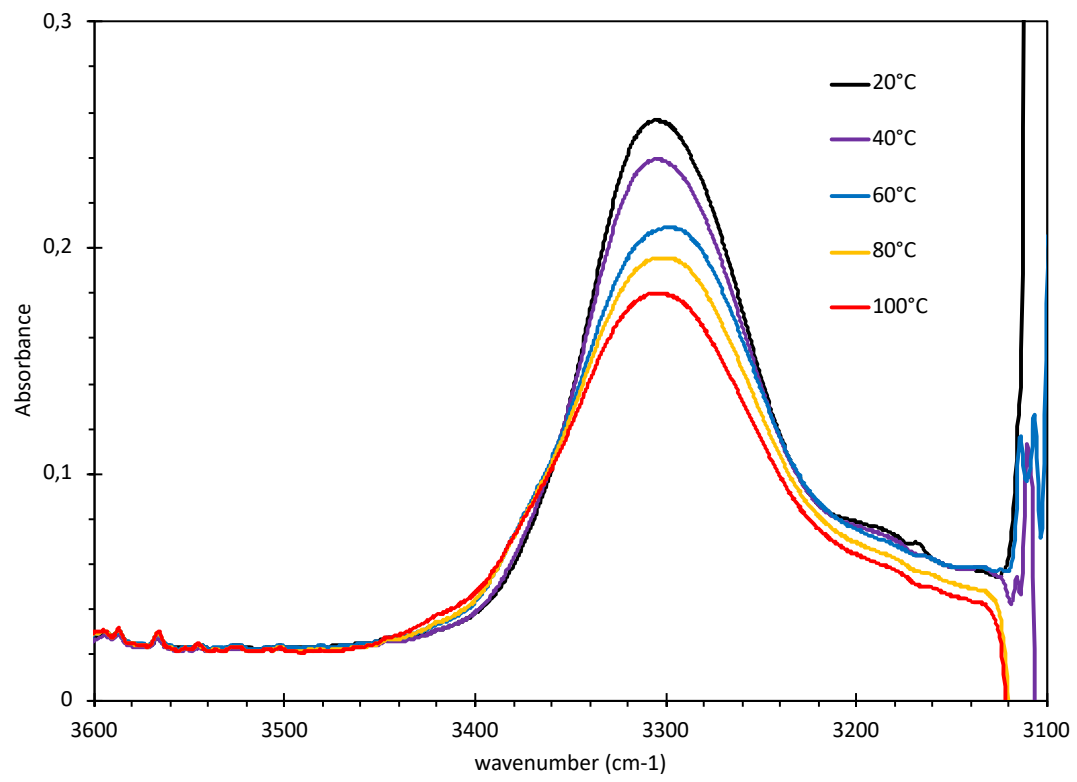

Figure S7. FTIR spectra versus temperature for $\mathrm{L}_{10}$ at $3 \mathrm{mmol} / \mathrm{L}$ in toluene. The free $\mathrm{N}-\mathrm{H}$ contribution $\left(3430 \mathrm{~cm}^{-1}\right)$ is very small compared to the hydrogen bonded $\mathrm{N}-\mathrm{H}$ contribution $\left(3300 \mathrm{~cm}^{-1}\right)$, even at $100^{\circ} \mathrm{C}$. 


\section{References}

1. Fonteneau, C.; Pensec, S.; Bouteiller, L. Versatile Synthesis of Reversible Combshaped Supramolecular Polymers. Polym. Chem. 2014, 5, 2496-2505.

2. Mellot, G.; Beaunier, P.; Guigner, J.-M.; Bouteiller, L.; Rieger, J.; Stoffelbach, F. Beyond Simple AB Diblock Copolymers: Application of Bifunctional and Trifunctional RAFT Agents to PISA in Water. Macromol. Rapid Commun. 2019, 40, 1800315.

3. Brown, W. Ed., Dynamic Light Scattering: The Method and Some Applications, Oxford University Press, Oxford, New York, 1993.

4. a) Young, C. Y.; Missel, P. J.; Mazer, N. A.; Benedek, G. B.; Carey, M. C. J. Phys. Chem. 1978, 82, 1375-1378. b) Schillen, K.; Brown, W.; Johnsen, R. M. Macromolecules 1994, 27, 4825-4832.

5. a) Charbonneau, C.; Lima, M. M. D. S.; Chassenieux, C.; Colombani, O.; Nicolai, T. Phys. Chem. Chem. Phys. 2013, 15, 3955-3964. b) Lefay, C.; Charleux, B.; Save, M.; Chassenieux, C.: Guerret, O.; Magnet, S. Polymer 2006, 47, 1935-1945. c) Lejeune, E.; Chassenieux, C.; Colombani, O. in Trends in Colloid and Interface Science XXIV, eds. V. Starov and K. Procházka, Springer, Berlin Heidelberg, 2011, pp. 7-16. d) Chassenieux, C.; Nicolai, T.; Durand, D. Macromolecules 1997, 30, 4952-4958. e) Han, S. Y.; Nicol, E.; Niepceron, F.; Colombani, O.; Pensec, S.; Bouteiller, L. Oligo-Urea with No Alkylene Unit Self-Assembles into Rod-Like Objects in Water. Macromol. Rapid Commun. 2019, 40, 1800698.

6. Brown, W. Light Scattering: Principles and Development, Clarendon Press, Oxford, U.K., 1996, vol. 53.

7. Brandrup, J.; Immergut, E.; Grulke, E.; Abe, A.; Bloch, D. R. Polymer Handbook (4 ${ }^{\text {th }}$ Edition); John Wiley\&Sons, 1999.

8. Pedersen, J. S. Adv. Colloid Interface Sci. 1997, 70, 171-210.

9. a) Terech, P.; Coutin, A. Langmuir 1999, 15, 5513-5525. b) Lortie, F.; Boileau, S.; Bouteiller, L.; Chassenieux, C.; Demé, B.; Ducouret, G.; Jalabert, M.; Lauprêtre, F.; Terech, P. Structural and rheological study of a bis-urea based reversible polymer in an apolar solvent. Langmuir 2002, 18, 7218-7222.

10. PerezFolch, J.; Subirana, J. A.; Aymami, J. Polar structure of $N, N$ '-dimethylurea crystals. J. Chem. Crystallogr. 1997, 27, 367-369. 